\title{
INEQUALITIES AND MONOTONICITY PROPERTIES FOR SOME SPECIAL FUNCTIONS
}

\author{
CHAO-PING CHEN
}

Abstract. The monotonicity, convexity, log-convexity and complete monotonicity properties for some special functions are proved, and some inequalities are established.

Mathematics subject classification (2000): 33B15, 26A48.

Keywords and phrases: Monotonicity, convexity, log-convexity, complete monotonicity, psi function, inequality.

\section{REFERENCES}

[1] Handbook of Mathematical Functions with Formulas, Graphs, and Mathematical Tables, M. Abramowitz and I. A. Stegun (Eds.), National Bureau of Standards, Applied Mathematics Series 55, 4th printing, with corrections, Washington, 1965.

[2] G. Allasia, C. GIORDANO AND J. PeČARIĆ, Inequalities for the gamma function relating to asymptotic expansions, Math. Inequal. Appl., 5, 3 (2002), 543-555.

[3] H. AlZER, IInequalities for the gamma and polygamma functions, Abh. Math. Sem. Univ. Hamburg, 68 (1998), 363-372.

[4] G. D. Anderson, R. W. Barnard, K. C. Richards, M. K. Vamanamurthy and M. VuoriNEN, Inequalities for zero-balanced hypergeometric functions, Trans. Amer. Math. Soc., 347, 5 (1995), 1713-1723.

[5] G. D. Anderson, M. K. Vamanamurthy and M. Vuorinen, Topics in special functions, P apers on analysis, 5-26, Rep. Univ. Jyväskylä Dep. Math. Stat., 83, Univ. Jyväskylä, Jyväskylä, 2001.

[6] D. W. DeTemple, A quicker convergence to Euler's constant, Amer. Math. Monthly, 100, 5 (1993), 468-470.

[7] A. M. FinK, Kolmogorov-Landau inequalities for monotone functions, J. Math. Anal. Appl., 90 (1982), 251-258.

[8] J.W.L. Glaisher, History of Euler's constant, Messenger of Math., vol. 1 (1872), p. 25-30.

[9] G. H. HARDY AND E. M. Wright, An Introduction to the Theory of Numbers, Oxford Science Publications, 1979.

[10] E. A. Karatsuba, On the computation of the Euler constant $\gamma$, Numer. Algorithms, 24 (2000), 83-97.

[11] A. Laforgia And P. NATAlini, On some Turán-type inequalities, J. Inequal. Appl., 2006, Art. ID 29828, 6 pp. Available online at http://www.hindawi.com/GetArticle.aspx?doi=10.1155/ JIA/2006/29828.

[12] S. R. Tims AND J. A. TyrRell, Approximate evaluation of Euler's constant, Math. Gaz., 55, 391 (1971), 65-67.

[13] D. V. Widder, The Laplace Transform, Princeton Univ. Press, Princeton, 1941.

[14] R. M. YounG, Euler's Constant, Math. Gaz., 75 (1991), 187-190. 